\title{
Laser Assisted Plasma Arc Welding
}

Phillip W. Fuerschbach

Sandia National Laboratories

Albuquerque, New Mexico, USA

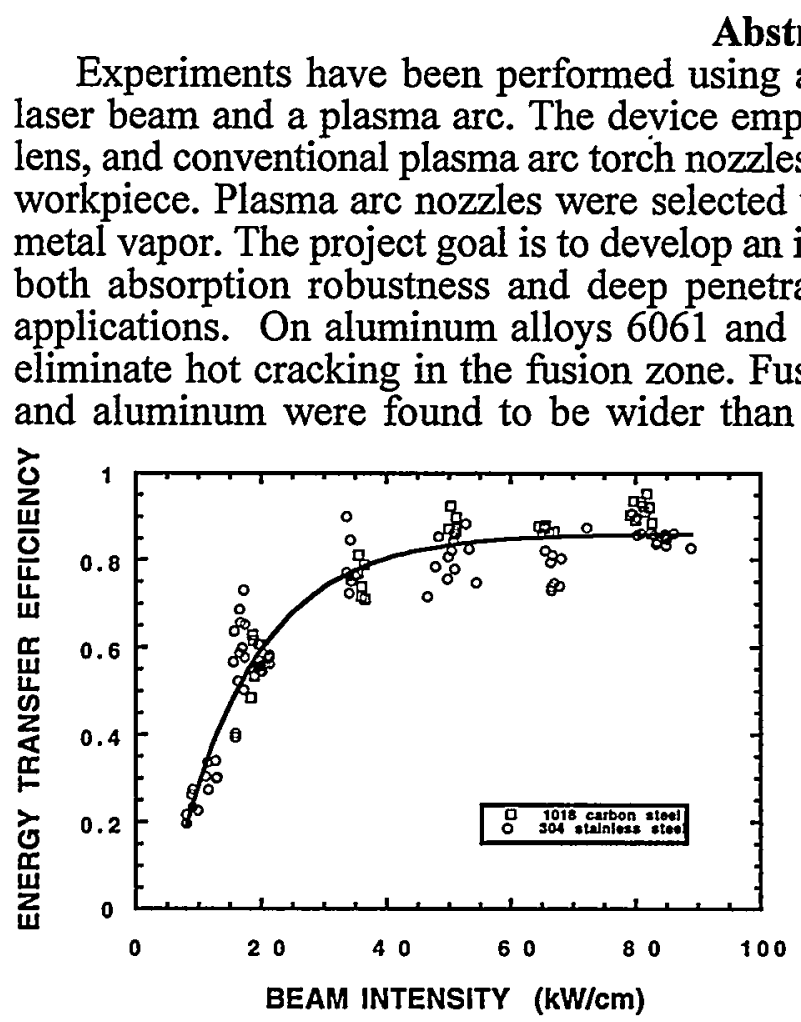

Fig.l - Variation in workpiece absorption for a $\mathrm{CO}_{2}$ laser. From Fuerschbach, Welding Journal, vol. 75, pp. 24s-34s, 1996.

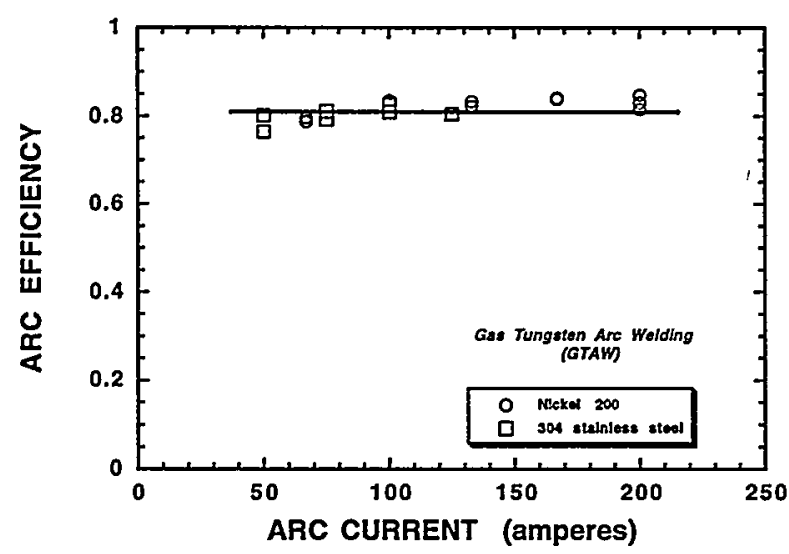

Fig.2 - Consistency in workpiece energy transfer for automated gas tungsten arc welding. From Fuerschbach and Knorovsky, Welding Journal, vol. 70, pp. 287s-297s, 1991. characteristic plasma arc welds.

\section{Project Goals \\ Introduction}

The employment of Laser Beam Welding (LBW) for joining many high reliability devices is often limited by fluctuations in energy transfer along the weld joint. Substantial changes in absorption and hence melting can be traced to variations in part fit-up, focus spotsize, surface finish, and presence of surface contaminants. Figure 1 shows the wide deviation in energy transfer efficiency that can occur for $\mathrm{CO}_{2}$ laser beam welding when laser beam irradiance is varied. Similar variations in absorption are known to occur with $\mathrm{Nd}$ :YAG materials processing lasers. In contrast, energy transfer efficiency in electric arc welding is relatively insensitive to changes in the welding environment as shown in Figure 2 . Electron absorption is distinctly different from photon absorption in this important characteristic. The consistency in melting obtained with arc welding is a quality attribute that requires painstaking process controls to duplicate with laser welding.

Yet the arc weld fusion zone is often too large, and the laser welding 


\section{DISCLAIMER}

This report was prepared as an account of work sponsored by an agency of the United States Government. Neither the United States Government nor any agency thereof, nor any of their employees, make any warranty, express or implied, or assumes any legal liability or responsibility for the accuracy, completeness, or usefulness of any information, apparatus, product, or process disclosed, or represents that its use would not infringe privately owned rights. Reference herein to any specific commercial product, process, or service by trade name, trademark, manufacturer, or otherwise does not necessarily constitute or imply its endorsement, recommendation, or favoring by the United States Government or any agency thereof. The views and opinions of authors expressed herein do not necessarily state or reflect those of the United States Government or any agency thereof. 


\section{DISCLAIMER}

Portions of this document may be illegible in electronic image products. Images are produced from the best available original document. 
advantages of deep penetration and small weld width cannot be obtained with arc welding. Hence, the applications for arc heat sources are not universal, and laser welding has become the process of choice for many welded products that can benefit from these characteristics. The laser is especially effective in controlling fusion zone dimensions with independent changes in the magnitude of laser beam irradiance.

As have many experimentalists earlier [1-4], we have endeavored to combine the laser and arc together into a hybrid process. The technical motivations of others through the years have been diverse, our goal is to develop an enhanced fusion welding process that exhibits both absorption robustness and deep penetration. To date, many experimental welds with the hybrid process have been made with parallel experimental goals of improving performance and gaining further insight into process fundamentals. A review of our important progress and results follows.

\section{Equipment}

The choice of laser for laser assisted arc welding will depend on the goal of the application. For small scale welding applications, a low power laser with only a few hundred watts of continuous power might be sufficient if the arc can provide the majority of melting energy. In practice, it is difficult to achieve keyhole-like penetration at low continuous power and considerably higher laser power levels are needed, or alternatively the use of a pulsed laser is necessary.

Since the majority of our development has been oriented towards small scale applications (required penetration depth less than $1.5 \mathrm{~mm}$ ), we opted for a Raytheon SS501 400W pulsed Nd:YAG laser for our initial process development. With this process we hoped to keep average power low and thereby utilize the arc for the bulk of the base metal heating. We also hoped that the pulsed laser would be useful in removing the tenacious surface oxide that makes welding aluminum so difficult. A short development effort was also conducted with a Photon Sources V1200 continuous wave slow flow $\mathrm{CO}_{2}$ laser.

Beam intensity and penetration can also be increased by selecting shorter focal length lenses - but the geometric constraints of combining heat sources in a hybrid process, in most cases will increase the focal length to $100 \mathrm{~mm}$ or longer. Small focused spot sizes are therefore difficult to obtain with the hybrid process. All of the pulsed Nd:YAG laser work used a $150 \mathrm{~mm}$ focal length lens with an estimated spot diameter of $0.50 \mathrm{~mm}$ [5]. The better beam quality of the $\mathrm{CO}_{2}$ laser enabled the use of $125 \mathrm{~mm}$ focal length lens with an estimated spot diameter of $0.22 \mathrm{~mm} \mathrm{[6]}$.

Initial arc welding was conducted with a Miller XMT-300 GTA constant current power

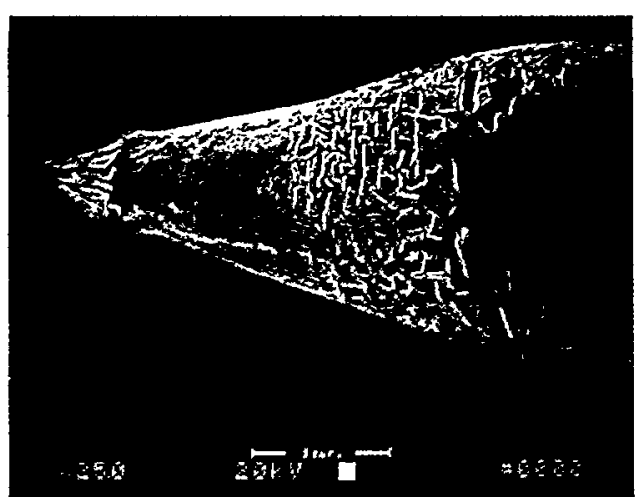

Fig. 3 - SEM pholo of tungsten electrode $\left(1.5 \% \mathrm{La}_{3} \mathrm{O}_{3}\right)$ after welding with the hybrid laser/GTAW process on GnKl aluminum. Contamination is nrimarilv Al vanor. supply. The arc power source used for remainder of the experiments was a Merrick Micropaw 100 ampere plasma arc power supply with water cooling and high frequency arc start. All arc welds were made in the continuous current mode.

\section{Weld trials with GTAW}

Results and Discussion

Initial experiments were conducted with a conventional GTA welding torch with a tungsten cathode oriented at an angle to the side of the focused pulsed Nd:YAG laser beam, similar to the set-up of Diebold and Albright [3]. These tests on 6061 aluminum indicated that the tungsten electrode could quickly become contaminated with aluminum vapor 


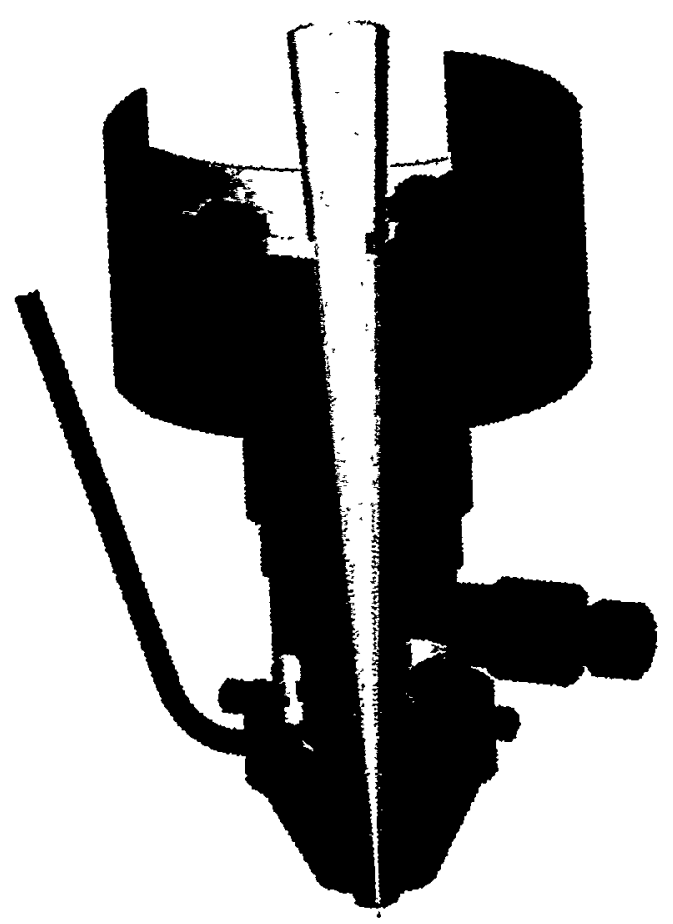

Fig.4 - Design prototype end-effector for hybrid laser/plasma arc welding. Arc and focused beam are directed coaxial through hollow tungsten electrode. from the laser beam keyhole cavity as shown in Fig. 3. It was revealed by EDS analysis that the contamination on the electrode was predominantly aluminum and not alloying elements such as magnesium. The process performance was significantly impaired by this vapor deposition and only shallow, nonkeyhole mode welds could be made without contamination of the electrode. Attempts to blow the metal vapor away from the tungsten with a side jet of inert gas were not successful. It is not known if this problem would persist with materials other than aluminum, but protecting the electrode from the laser vaporized metal is clearly a requirement. The natural protection of the tungsten electrode behind a nozzle in a plasma arc torch made plasma arc welding the next obvious choice. [7]

\section{Hollow Electrode Plasma Arc}

Early work with the GTA torch also indicated that positioning the arc from the side would seriously impair the flexibility of the process for robotic and non-linear joint applications. To obtain omni-directional motion, it was decided that both the laser beam and arc need to be coaxial. To facilitate this, a hollow tungsten electrode was fabricated and the laser beam was transmitted through and focused just below the tip of the electrode. Our approach is similar in concept to devices by Inoue [8] and by Dykhno et al [9]. To protect the hollow electrode, we developed an end-effector with a replaceable plasma arc nozzle to shield the tungsten from the laser keyhole vapor by directing an internal flow of inert gas around the electrode. This arrangement requires the focused laser beam to pass through both the electrode and the plasma nozzle while still remaining focused when striking the workpiece below. Therefore, good beam quality is important and a lens focal length of $150 \mathrm{~mm}$ was needed for a $200 \mathrm{~W}$ pulsed Nd:YAG beam to pass through.

The end-effector necessarily includes connections for plasma gas, shielding gas, and a low current pilot arc. Our design prototype is shown in Fig. 4. An important technical challenge in the construction of the end-effector was creating laminar flow of inert gas around the tungsten electrode. The close spacing between the electrode and the exit nozzle has required several design iterations to achieve proper flow characteristics and still permit laser beam transmission through these components. High voltage breakdown within the end-effector
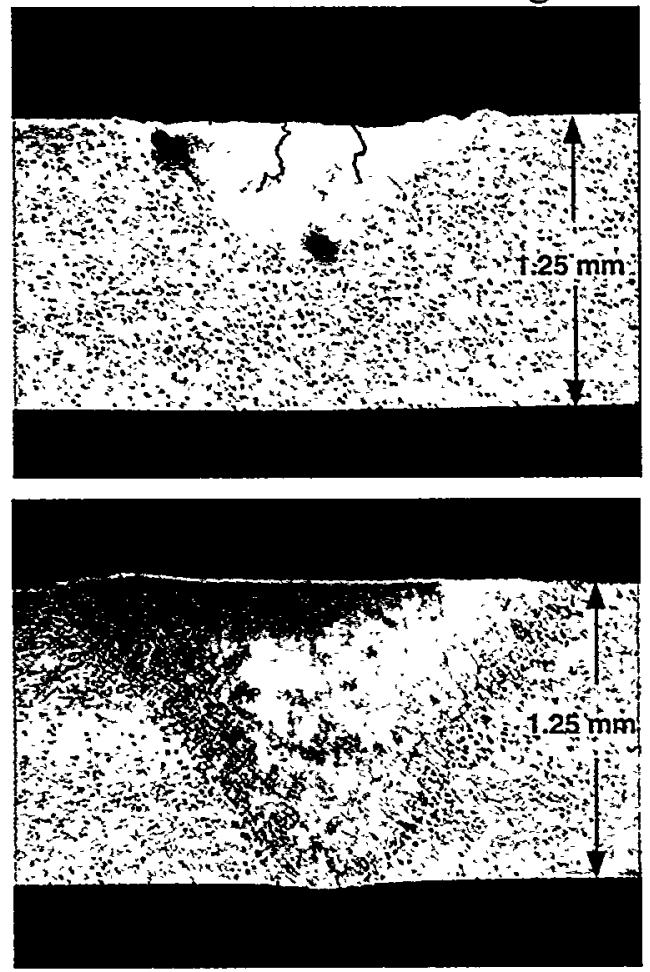

Fig. 5 (a) laser weld only, 16.7J, 200W, $7.2 \mathrm{~ms} \mathrm{(b)}$ hybrid weld same laser conditions, with $40 \mathrm{~A}, \sim 640 \mathrm{~W}$ nlasma arc 
during pilot arc starting also has been a problem in several designs. Strategic placement of electrical insulators to prevent internal arcing has proved advantageous in overcoming this problem.

\section{Weld trials on aluminum alloys}

Welds with the hybrid laser/plasma process revealed that solidification cracking in aluminum alloys can be eliminated by the addition of a continuous power arc to the pulsed laser beam. This is an important benefit of the hybrid process that was anxiously anticipated. Welds on $1.27 \mathrm{~mm} 6061$ Aluminum sheet both with and without the arc are shown in Fig. 5(a,b). Hot cracks are visible in the fusion zone in Fig. 5(a) as is typical for autogenous pulsed Nd:YAG welds on this high strength aluminum alloy. However in Fig. 5(b), the addition of the continuous power arc eliminates the hot cracking. These results are consistent with earlier work by Cieslak and Fuerschbach [10] which found welds in several aluminum alloys were cracked with a pulsed Nd:YAG laser but could be made crack free with a continuous wave Nd:YAG laser. By slowing the solidification and cooling rate, the weld metal shrinkage strains are reduced and hot cracks are avoided.

In addition, the hybrid process 6061 aluminum weld in Fig. 5(b) has a fusion zone that is substantially deeper and larger than the laser weld in Fig. 5(a) due to the synergistic effect of the plasma arc. For improved joint gap tolerance, a somewhat wider weld is desired for many laser weld applications. The increased weld width obtained with the hybrid heat source is perhaps an important indicator of enhanced process robustness. Broad welds with relatively deep weld penetration have been achieved as anticipated. The weld dimensions seen in Fig. 5(b) certainly could not be obtained with a conventional arc welding heat source. The center of the weld pool is clearly deeper with a greater depth to width ratio than one would expect to see using either a plasma or GTA torch. Likewise, it is unlikely that a pulsed Nd:YAG laser weld would exhibit the same weld dimensions seen in Fig. 5(b). The hybrid process enables unique weld geometries to be achieved, quite unlike those to be obtained with conventional heat sources.

The hybrid process was marginally successful in removing the tenacious surface oxide on aluminum with the tungsten as the arc cathode. Direct current GTA welds with electrode negative are usually unsatisfactory because the weld pool remains viscous due to the presence of aluminum oxide. The laser/plasma welds did not appear shiny as one would observe with robust oxide removal, but many of the welds did have a smooth surface which indicates that some of the oxide was removed by the laser. The oxide removal was expected since pulsed Nd:YAG laser welds on aluminum are noted for a shiny appearance resulting from vigorous oxide removal in the high intensity pulsed beam. Unfortunately with the characteristic duty cycle of a pulsed laser beam no greater than $10 \%$, the pulsed beam can only remove the oxide for a small period of time. As the laser/plasma weld pool becomes large, less of the oxide can be removed by the laser and the welds may become less fluid as shown in Fig. 6, The

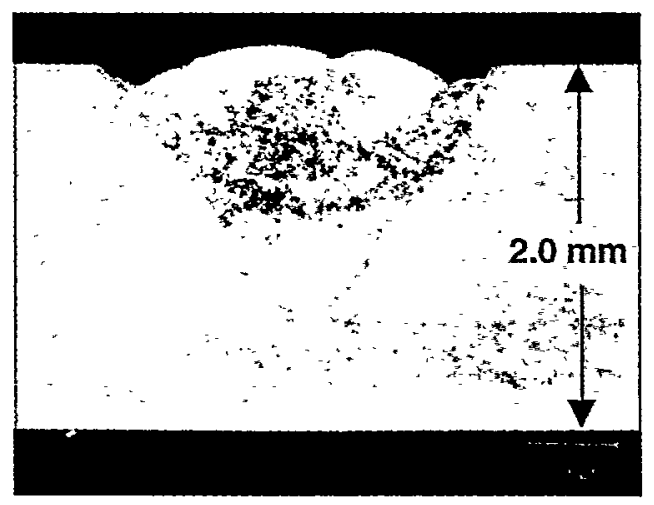

Fig. 6- Hybrid laser/plasma weld on $6111 \mathrm{Al}$. $10 \mathrm{~J}, 200 \mathrm{~W}, 3.1 \mathrm{~ms}, 40 \mathrm{~A}$ arc: $~ 640 \mathrm{~W}, 10 \mathrm{~mm} / \mathrm{s}$. partial penetration weld on $2.0 \mathrm{~mm}$ thick $6111 \mathrm{Al}$ exhibits undercut and a weld surface that is somewhat rough due to the presence of aluminum oxide in the fusion zone. It is known that alternating current welds with variable electrode polarity can remove the oxide from aluminum but with a DC power supply and a very unconventional plasma torch this approach was not workable. 

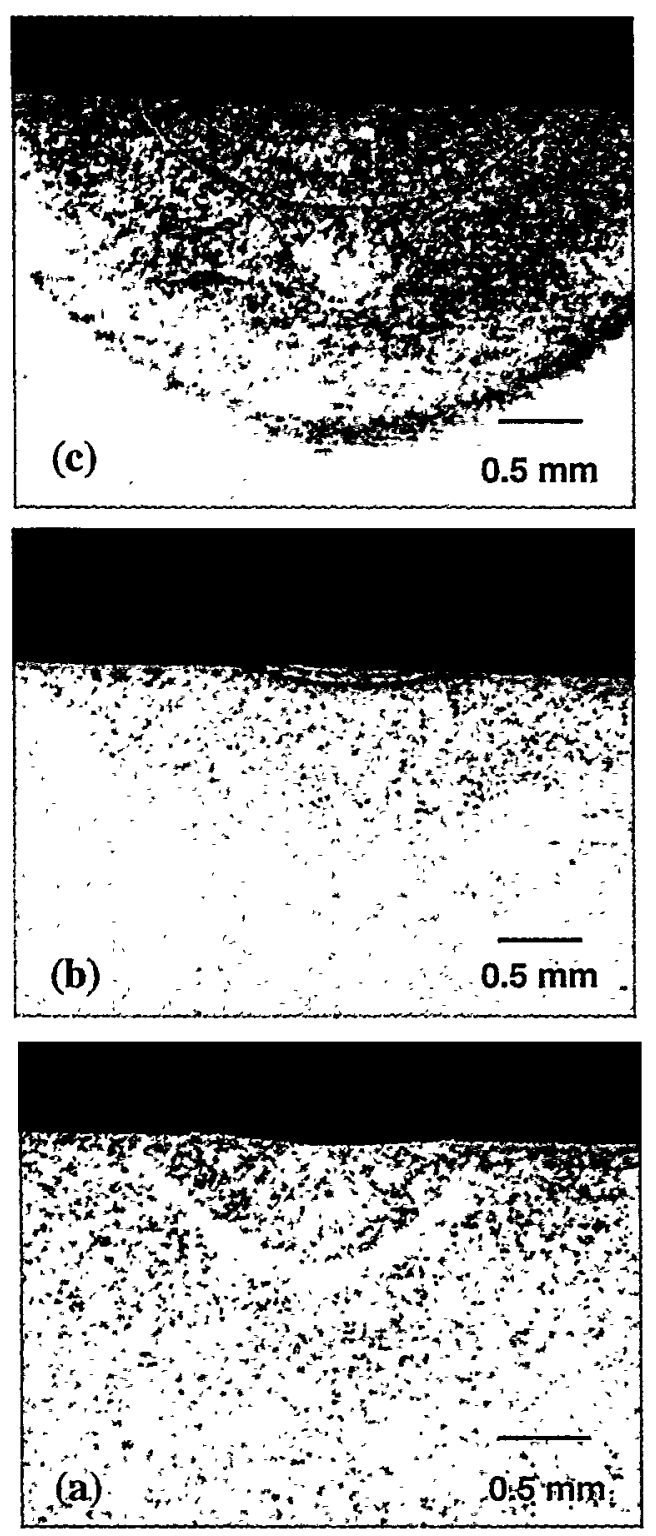

Fig. 7-17-4PH stainless steel, $5.1 \mathrm{~mm} / \mathrm{s}$. (a) laser only, 6.7J, 100W, $7.2 \mathrm{~ms}$. (b) arc only, $25 \mathrm{~A}$ : $\sim 400 \mathrm{~W}$. (c) hybrid, same laser and arc conditions.
It is interesting that these hybrid welds are characterized by laser pulse ripples that extend throughout the fusion zone and well beyond the location of the focused laser beam. The ripples indicate that a large weld pool is likely maintained between laser pulses. Unfortunately the presence of large weld pool is also a disadvantage with a pulsed laser since spatter on the workpiece surface can be expected when the laser pulse strikes a molten pool. In fact our efforts to obtain deep penetration in aluminum were limited due to the appearance of weld metal spatter on the sample surface. Surface spatter usually results in a corresponding increase in fusion zone discontinuities as well. For this reason, it is expected that the quiescent weld pool that is representative of continuous wave laser welding may be preferable for deep penetration welding with the hybrid laser/plasma process.

\section{Weld trials on Steel alloys}

Some of the advantages of the hybrid process noted above for welding aluminum are also important advantages for the welding of steel alloys. Hot cracking can be especially problematic with pulsed laser welding of stainless steels, and gap filling fusion zone geometries are similarly desired in steel welding applications. The synergy of the hybrid laser/plasma process on 17-4PH stainless steel can be seen in Fig. 7(a,b,c). It is clear in comparing Fig. 7(a) to Fig. 7(b) that the plasma arc does not create the same small heat affected zone as the pulsed laser. As expected, when the two processes are combined as in Fig. 7(c), the larger heat affected zone is retained. While not apparent in the aluminum welds in Figs. 5 $\& 6$, greater heat input and a larger thermal profile are unavoidable consequences of the hybrid process.

Fig. 7(c) also indicates that the hybrid process may in some instances create conditions more favorable to keyhole mode penetration. The greater penetration

depth in Fig. 7(c) when compared with Fig. 7(b) is indicative of a transition from conduction mode to penetration mode. The synergy of the two processes clearly has helped enable this transition. Unlike aluminum alloys, steel alloys do not have a tenacious surface oxide that must be removed before smooth weld pools can be achieved. Undercut can still be a problem, but the weld pools are for the most part smooth and more cosmetically appealing than the hybrid welds made on aluminum alloys.

The hybrid process welds on stainless steel had the best depth to width ratio as evidenced in Fig. 8. It

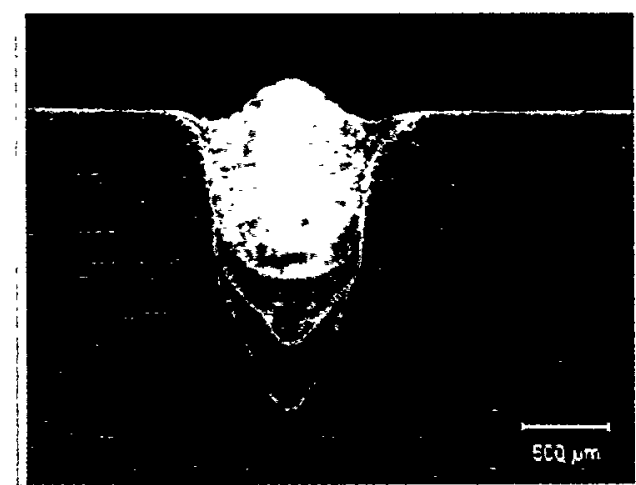

Fig.8 - Hybrid laser/plasma weld on 304 stainless steel. $6,150 \mathrm{~W}, 5 \mathrm{~ms}, 5.1 \mathrm{~mm} / \mathrm{s}, 20 \mathrm{~A}$ arc: $\sim 320 \mathrm{~W}$. 
is clear that the arc can be made to penetrate much deeper into the weldment with the addition of the laser beam. The $1.75 \mathrm{~mm}$ penetration depth obtained with the hybrid process is significantly deeper than either the arc or laser could solely achieve. Indeed, the upset weld metal that protrudes above the workpiece surface in Fig. 8 is representative of many keyhole mode electron beam welds. The presence of multiple weld ripples in Fig. 8 also indicates that the entire weld pool is molten after the incidence of each laser pulse. As noted for the aluminum welds, the hybrid melt front may extend well beyond the position of the focused laser beam.

The synergy of the laser and arc shown in Fig. 8 was not as encouraging for other process conditions. The welds in Fig. $9(a, b, c)$ indicate the effect of arc current on the weld geometry. It is apparent that as the arc current is increased, there is little synergy between the arc and the laser, moreover, the arc appears to be superimposed upon the underlying laser weld. The laser pulse ripples do not extend across the weld pool as in Fig. 8, and the arc appears to be too large relative to the size of the laser beam. It is postulated that despite the similarity in conditions, the weld shape difference between Fig. 8 and Fig. 9(a) is due to the $17 \%$ lower pulse energy in Fig. 9(a); the laser simply has not penetrated the workpiece as deeply and the arc anode spot has failed to penetrate as well. The higher current welds in Fig. 9(b) and Fig. 9(c) also have failed to penetrate deeply despite a substantial increase in arc power. The lack of penetration may be attributable to an enlarged arc anode spotsize
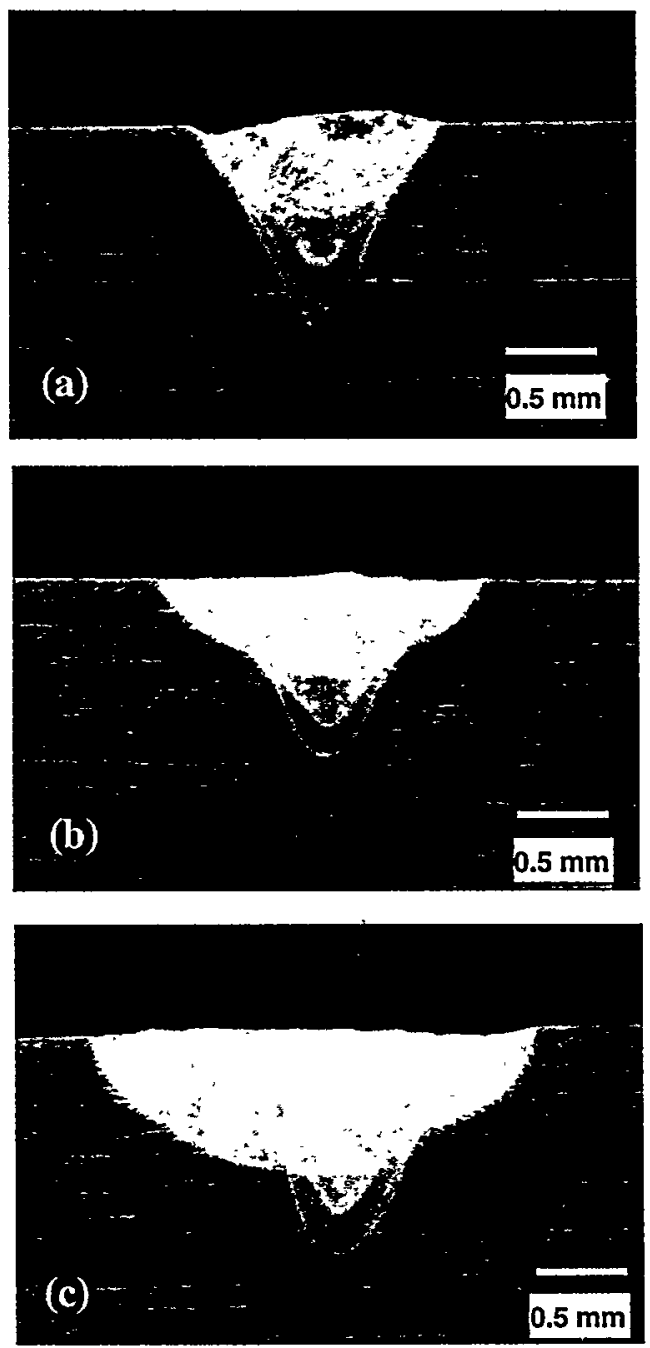

Fig.9 - Effect of arc current on 304 stainless steel weld dimensions. (a) $20 a$ (b) $30 \mathrm{~A}$ (c) 40A. All at 5J, $150 \mathrm{~W}, 5 \mathrm{~ms}, 5.1 \mathrm{~mm} / \mathrm{s}$.

which is known to occur as arc current is increased. These weld cross-sections are instructive because they indicate that focusing of the arc by the laser beam can be achieved as shown in Fig. 8, yet focusing of the arc is not always assured with the hybrid process as shown in Fig. 9(b) and Fig. 9(c).

\section{Weld trials with a Continuous Wave $\mathrm{CO}_{2}$ Laser}

To test the hybrid process with a continuous wave laser, the plasma arc power supply and prototype end-effector were interfaced to a Photon Sources $\mathrm{CO}_{2}$ laser and fitted with a $125 \mathrm{~mm}$ focal length $\mathrm{Zn}$-Se meniscus lens. The choice of this laser was again made with the goal of obtaining small scale hybrid welds with a low fraction of laser power. The excellent beam quality of this laser makes possible keyhole mode welds with less than $1 \mathrm{~mm}$ penetration as shown in Fig. 10(a). Unfortunately the hybrid weld made at the same laser conditions in Fig. 10(b) has actually penetrated less into the base metal and no synergistic increase in melting is apparent. Other trials with the $\mathrm{CO}_{2}$ laser at powers up to 900 watts and with arc currents up to $40 \mathrm{~A}$ also failed to improve the hybrid process performance.

One may infer from Fig. 10(b) that the arc plasma is interfering with the transmission of the focused laser beam as reported by Bibik et al, [11]. Absorption or defocusing of the laser beam in the coaxial arc plasma is indicated. The excitation of electrons in the $\mathrm{CO}_{2}$ laser weld 
vapor plume by the absorption of laser photons is a recognized [12] source of beam attenuation known as inverse Bremsstrahlung. At the $\mathrm{CO}_{2}$ laser frequency decoupling of the
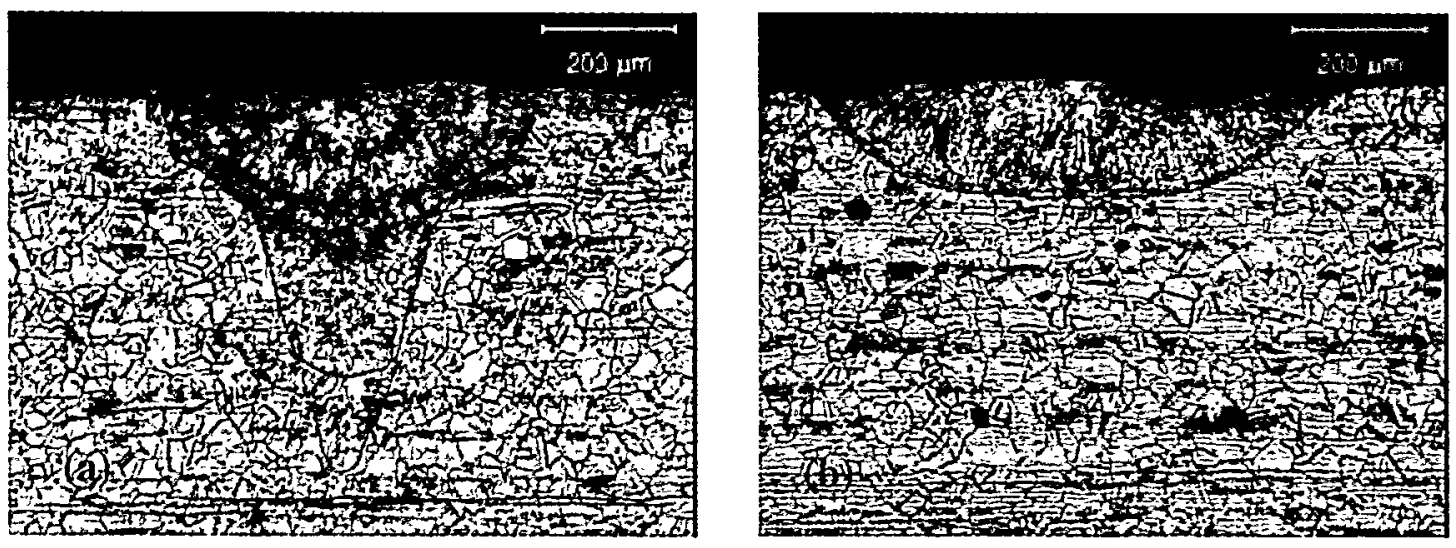

Fig. 10 - (a) 304 stainless steel continuous wave CO2 laser weld, $240 \mathrm{~W}, 21 \mathrm{~mm} / \mathrm{s}$, Ar shield. (b)

hybrid laser/plasma weld, same laser conditions, $20 \mathrm{~A}$ arc: $\sim 320 \mathrm{~W}$.

laser beam from the surface often occurs and special plasma control devices are used to control the problem. Since the arc plasma is the likely source of electrons, it is unclear how plasma attenuation can be avoided with the hybrid process, and no remedies to improve performance of the hybrid end-effector with the $\mathrm{CO}_{2}$ laser were tried.

\section{Summary}

An end-effector has been designed and constructed to investigate the appropriateness of the hybrid laser/arc process for small scale welding applications. Fusion zone dimensions were found to be wider than typical laser welds and deeper than typical plasma arc welds. Aluminum alloys 6061 and 6111 were welded without solidification cracking due to the slower cooling rate of the hybrid process. We have to date operated the hybrid process primarily with a power balance of $25 \%$ laser power and $75 \%$ arc power. Our design goal of maintaining constant energy absorption for any weld joint gap is consistent with this balance of power. Due to the considerable complexities of this process development, especially with regard to end-effector design improvements, weld applications to test the process robustness are yet to be undertaken.

\section{Acknowlegments}

The author would like to thank Fred Hooper for his insightful assistance during the experiments and his important contributions to the end-effector design. The valuable assistance of Oszkar Rohosy in power supply linking and in pulsed Nd:YAG beam characterization is also appreciated. This work completed at Sandia National Laboratories. Sandia is a multiprogram laboratory operated by Sandia Corporation, a Lockheed Martin Company, for the United States Department of Energy under Contract DE-AC0494AL85000.

\section{References}

[1] W. M. Steen, "Arc Augmented Laser Processing of Materials," J. Appl. Phys., vol. 51, pp. 5636-5641, 1981.

[2] J. Matsuda, A. Utsami, M. Katsumura, M. Hamasaki, and S. Nagata, "TIG or MIG Arc Augmented Laser Welding of Thick Mild Steel Plate," Joining and Materials, pp. 31-34, 1988.

[3] T. P. Diebold and C. E. Albright, "Laser-GTA Welding of Aluminum Alloy 5052," Welding Journal, vol. 63, pp. 18-24, 1984. 
[4] K. H. Magee, V. E. Merchant, and C. V. Hyatt, "Laser Assisted Gas Metal Arc Weld Characteristics," presented at ICALEO, 1990.

[5] P. W. Fuerschbach and M. Essien, "Beam-Quality Measurements for Materials Processing Lasers and the Proposed ISO Standard," presented at ICALEO, Orlando, Florida, 1993.

[6] M. Essien and P. W. Fuerschbach, "Beam Quality of a Materials Processing CO2 Laser," Welding Journal, vol. 75, pp. 47s-54s, 1996.

[7] R. P. Walduck and J. Biffin, "Plasma Arc Augmented Laser Welding," Welding Research Abroad, vol. 41, 1995.

[8] K. Inoue, "Laser Machining Apparatus," . United States Patent: Inoue-Japax Research Incorporated, 1987.

[9] I. S. Dykhno, I. U. Krivtsun, and G. M. Ignatchenko, "Combined Laser and Plasma Arc Welding Torch," . United States Patent, 1997.

[10] M. J. Cieslak and P. W. Fuerschbach, "On the Weldability, Composition, and Hardness of Pulsed and Continuous Nd:YAG Laser Welds in Aluminum Alloys 6061, 5456, and 5086," Metallurgical Transactions, vol. 19B, pp. 319-329, 1988.

[11] O. B. Bibik, V. N. Brodyagin, and Y. P. Pokladov, "Special features of Interaction of Laser Radiation with the Electric Wlding Arc in the combined Laser-Arc welding Process," Fizik i Khimiya Obrabotki Materialov, vol. 24, pp. 95-98, 1990.

[12] W. W. Duley, Laser Welding. New York: John Wiley \& Sons, 1999. 